\title{
Assessing Change in Cognitive Function in Dementia: The Relative Utilities of the Alzheimer's Disease Assessment Scale - Cognitive Subscale and the Cognitive Drug Research System
}

\author{
Keith A. Wesnes \\ Cognitive Drug Research Ltd., Goring-on-Thames, and Human Cognitive Neuroscience Unit, Northumbria \\ University, Newcastle upon Tyne, UK; Brain Sciences Institute, Swinburne University, Hawthorn, Vic., Australia
}

\section{Key Words}

The Cognitive Drug Research system • Alzheimer's Disease Assessment Scale - Cognitive Subscale • Alzheimer's disease $\cdot$ Dementia with Lewy bodies $\cdot$ Parkinson's dementia

\section{Abstract}

This paper considers the suitability of the Alzheimer's Disease Assessment Scale - Cognitive Subscale (ADAS-cog) as the gold standard in registration trials of treatments for Alzheimer's disease. Working groups have recommended replacing the ADAS-cog if suitable automated alternatives can be found. This paper makes the case for the Cognitive Drug Research (CDR) computerised cognitive assessment system, as an example of a suitable instrument to replace the ADAS-cog. The CDR system has been widely used in dementia work for 20 years and shows good correlations to the ADAS-cog, while additionally assessing the domains of attention, working memory, information processing and retrieval speed of information held in memory. The utility of the system in evaluating and differentiating the major dementias will be described, as well as its ability to track deterioration over time. Its validation as a core measure of cognitive dysfunction in the dementias will be described, as will work showing that various CDR measures relate closely to activities of daily living. The sensitivity of the CDR system to anticholinesterases will be described in Alzheimer's disease, dementia with Lewy bodies and Parkinson's dementia. Finally, the CDR system has a large normative database which allows treatment effects in dementia to be put into an unambiguous clinical perspective.

Copyright $\odot 2008$ S. Karger AG, Base

While the Alzheimer's Disease Assessment Scale Cognitive Subscale (ADAS-cog) is widely accepted as the gold standard in registration trials of treatments for Alzheimer's disease (AD), there is no regulatory mandate for this. The strengths of the ADAS-cog are its history of use and ability to assess important aspects of cognition such as memory. However, these are overshadowed by its numerous weaknesses [1], which include: the subjective nature of several of the assessments; the fact that it fails to assess several core deficits of $\mathrm{AD}$ including attention, information processing and speed of retrieval of information held in memory; the absence of formal parallel forms; the time taken to administer it; the specialist training required for administrators; its relative insensitivity, and its failure in many recent trials to reliably identify

\section{KARGER \\ Fax +4161306 1234 \\ E-Mail karger@karger.ch}

www.karger.com
(C) 2008 S. Karger AG, Basel

1660-2854/08/0054-0261\$24.50/0

Accessible online at:

www.karger.com/ndd
Prof. Keith A Wesnes, PhD

Cognitive Drug Research Ltd., CDR House

Gatehampton Road

Goring-on-Thames RG8 0EN (UK)

Tel. + 441491878 700, Fax +44 1491878 701, E-Mail keithw@cognitivedrugresearch.com 
declines over 6-month treatment periods in placebotreated patients, which makes it unsuitable for drugs targeted at basic disease-modifying mechanisms.

In 1997, the International Working Group on Harmonisation of Dementia Drug Guidelines published a position paper on objective testing in dementia trials [2]. The group recommended that besides memory, domains which should be assessed in future trials should include attention and information processing. Further, they recommended that computerised procedures should be used together with the established procedures in the field (e.g. the ADAS-cog) so that the comparable utility and sensitivity of the two types of testing could be identified. If clear advantages of computerised procedures were demonstrated, computerised procedures could supersede existing methods.

The Cognitive Drug Research (CDR) system is a laptop-based set of cognitive tests which has been in use in worldwide clinical trials for over 20 years. As recommended by Ferris et al. [2], the verbal or numeric test stimuli are presented on the computer screen in large clear fonts, and the patient does not respond via the keyboard, instead responses are made via a response box containing a NO and a YES button. The system comprises tests of attention (simple and choice reaction time, digit vigilance), working memory (spatial and articulatory) and episodic memory (word recall and recognition, picture recognition). The administrator reads preset instructions for each task to the patient, and only initiates the test when sure the patient is ready and understands what to do. The system automatically selects the appropriate parallel forms of the tests each time the patient is assessed, and the data are recorded automatically on encrypted files. The CDR system has been extensively validated in the dementias [3]. It has shown good testretest reliability, excellent criterion validity, discriminant validity and construct validity $[3,4]$. The establishment of the construct validity of the system identified five core domains of cognitive function that the system assesses - the abilities to focus and sustain attention, hold information in working memory and episodic memory, and the time taken to retrieve information from memory. It can identify significant cognitive deficits in untreated patients over 6 months in core domains of attention and speed of retrieval of information held in memory, and over only 3 months in the ability to store, retain and retrieve information in verbal and pictorial episodic secondary memory [5]. It can be administered by non-specialists, has more than 20 parallel forms, over 45 language versions, takes only $25-30 \mathrm{~min}$ to complete and is compli- ant with regulatory requirements such as 21 CFR Part 11. The system thus has the utility the ADAS-cog lacks to reliably track performance changes over hours, days or weeks. The domain scores of the system have been validated by factor analysis [4] and have been shown to correlate with cerebrospinal fluid levels of tau and $A \beta_{42}$. Importantly, attention measures from the CDR system have been demonstrated to have strong predictability for the ability to conduct the activities of daily living in demented patients, particularly in comparison to the ADAS-cog [6]. Further, the ability of the system to measure separate cognitive domains gives it two important advantages over the ADAS-cog. Firstly, it has enabled the CDR system to demonstrate differences in the cognitive profile of impairments in various dementias including $\mathrm{AD}$, vascular dementia, dementia with Lewy bodies, Parkinson's dementia and Huntington's disease [7-9]. Secondly, it enables treatment-induced benefits to particular domains, e.g. attention, to be identified. Another advantage of a computerised system is the enormous benefits to data management, particularly in large international trials. A disadvantage of any computerised system in contrast to the ADAS-cog is that clinicians are very familiar with the ADAS and are often skeptical about automated tests.

The sensitivity of the CDR system to improvements in cognitive function has been demonstrated in AD patients with donepezil, velnacrine, galantamine, tacrine and S-12024 [10]. In one trial, benefits with galantamine started to appear after 4 weeks [11]. In both dementia with Lewy bodies $[4,12]$ and Parkinson's dementia [13, 14], improvements have been seen with both rivastigmine and donepezil [15]. The use of the CDR system in pivotal trials in dementia with Lewy bodies and Parkinson's dementia has drawn favourable editorial comments in both the Lancet [16] and New England Journal of Medicine [17].

In terms of establishing effect sizes and clinical relevance, the CDR system has the huge advantage over the ADAS-cog of having a large normative database of over 6,000 healthy volunteers from 18 to 87 years of age. It is thus possible to identify the actual magnitude of cognitive impairment in patients prior to treatment, and thus to determine how much patients are moved by treatment towards being normal for their age [10]. Thus in AD, 12 weeks' treatment with galantamine has shown the ability to move the patients $30 \%$ closer towards being normal for their age [11]. In dementia with Lewy bodies, rivastigmine moved the patients approximately $50 \%$ towards being normal for their age on a core measure of attention [4], while in Parkinson's dementia, rivastigmine moved 
the patients between 24 and $69 \%$ towards being normal for their age on four key measures of attention [14].

The CDR system thus has the utility, reliability and practicality to be included in any trial design in the dementias. Its sensitivity in relatively small trials makes it extremely useful in phase II trials and of course in pivotal trials. Finally, its ability to predict the activities of daily living and the opportunity to fully identify the clin- ical benefit of treatment by determining exactly how much patients are moved towards being normal for their age makes it the natural successor to the ADAS-cog. It is now being included in a range of high-profile trials, particularly those with nicotinic agonists, and these are expected to confirm its suitability as a primary outcome measure in dementia research.

\section{References}

1 Wesnes K, Harrison J: The evaluation of cognitive function in the dementias: methodological and regulatory considerations. Dialogues Clin Neurosci 2003;5:77-88.

-2 Ferris S, Lucca U, Mohs R, Dubois B, Wesnes K, Erzigkeit H, Geldmacher D, Bodick N: Objective psychometric tests in clinical trials of dementia drugs. Position paper from the International Working Group on Harmonization of Dementia Drug Guidelines. Alzheimer Dis Assoc Disord 1997;11(suppl 3):34-38.

-3 Simpson PM, Surmon DJ, Wesnes KA, Wilcock GK: The Cognitive Drug Research computerised assessment system for demented patients: a validation study. Int J Geriatr Psychiatry 1991;6:95-102.

4 Wesnes KA, McKeith IG, Ferrara R, Emre M, Del Ser T, Spano PF, Cicin-Sain A, Anand $\mathrm{R}$, Spiegel R: Effects of rivastigmine on cognitive function in dementia with Lewy bodies: a randomised placebo-controlled international study using the Cognitive Drug Research computerised assessment system. Dement Geriatr Cogn Disord 2002;13:183192.
5 Wesnes KA, Harrison J, Edgar C, Pincock C: The sensitivity and reliability of the Cognitive Drug Research computerised cognitive assessment system to disease progression and treatment response in Alzheimer's disease. Int Psychogeriatr 2005;17(suppl 2):154.

-6 Bronnick K, Ehrt U, Emre M, De Deyn PP, Wesnes K, Tekin S, Aarsland D: Attentional deficits affect activities of daily living in dementia associated with PD. J Neurol Neurosurg Psychiatry 2006;77:1136-1142.

7 Mohr E, Walker D, Randolph C, Sampson M, Mendis T: The utility of clinical trial batteries in the measurement of Alzheimer's and Huntington's dementia. Int Psychogeriatr 1996;8:397-411.

8 Walker MP, Ayre GA, Cummings JL, Wesnes K, McKeith IG, O’Brien JT, Ballard CG: Quantifying fluctuation in dementia with Lewy bodies, Alzheimer's disease and vascular dementia. Neurology 2000;54:16161625.

-9 Zaffalon M, Wesnes K, Petrini O: Reliable diagnosis of dementia by the naïve credal classifier inferred from incomplete cognitive data. Artif Intell Med 2003;29:61-79.

10 Wesnes K: The role of attention deficits in the cognitive pathology of dementia. Alzheimer Insights 2001;7:1-4.

11 Vellas B, Cunha L, Gertz HJ, De Deyn PP, Wesnes K, Hammond G, Schwalen S: Early onset effects of galantamine treatment on attention in patients with Alzheimer's disease. Curr Med Res Opin 2005;21:1423-1429.
12 McKeith I, Del Ser T, Spano P, Emre M, Wesnes K, Anand R, Cicin-Sain A, Ferrara R, Spiegel R: Efficacy of rivastigmine in dementia with Lewy bodies: a randomised, double-blind, placebo-controlled international study. Lancet 2000;356:2031-2036.

13 Emre M, Aarsland D, Albanese A, et al: Rivastigmine for dementia associated with Parkinson's disease. N Engl J Med 2004; 351:2509-2518.

14 Wesnes KA, McKeith IG, Edgar C, Ferrara R, Emre M, Lane R: Benefits of rivastigmine on attention in dementia associated with Parkinson disease. Neurology 2005;65:16541656.

15 Rowan E, McKeith IG, Saxby BK, Newby, Daniel S, Sanders J, Wesnes KA: Effects of donepezil on central processing speed and attentional measures in Parkinson's disease with dementia and dementia with Lewy bodies. Dement Geriatr Cogn Disord 2007;23: 161-167.

16 Cummings JL: Commentary, cholinesterase inhibitors: expanding applications. Lancet 2000;356:2024-2036.

17 Press DZ: Parkinson's disease dementia - A first step? N Engl J Med 2004;351:25472549. 